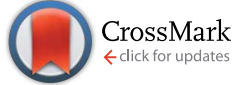

Cite this: RSC Adv., 2017, 7, 17724

Received 4th February 2017

Accepted 16th March 2017

DOI: $10.1039 / \mathrm{c} 7 \mathrm{ra01429e}$

rsc.li/rsc-advances

\section{Effect of copper oxide shell thickness on flash light sintering of copper nanoparticle ink $\dagger$}

\author{
Gyung-Hwan Oh, ${ }^{a}$ Hyun-Jun Hwang ${ }^{a}$ and Hak-Sung Kim*ab
}

In this study, the effect of the thickness of a copper oxide-shell on flash light sintering of Cu nanoparticles (NPs) was investigated. The electrical properties of Cu nano-ink films with various oxide-shell thicknesses were examined by measuring the sheet resistance. Furthermore, the amount of PVP in the Cu NP-ink was varied to reduce the copper oxide-shell efficiently and enhance the flash light sintering of the Cu NPs. Also, to investigate the reduction and sintering phenomena of Cu NPs with respect to the copper oxide shell thickness, the sheet resistances of the Cu films were measured in real-time using an in situ resistance measuring system during the flash light sintering process. The results of this study established the maximum allowable thickness of the copper oxide shell that allows flash light sintering and also provided the optimal amount of PVP in Cu nano-ink for a particular copper oxide shell thickness.

\section{Introduction}

Recently, printed electronics have received increased attention as an alternative manufacturing process for electronic devices such as radio frequency identification (RFID) tags, wearable electronics, and solar cells ${ }^{\mathbf{1 , 2}}$ because of their rapid and low-cost processing compared to the conventional photolithographic processes. ${ }^{3}$ The core technologies for printed electronics, including nanomaterial-based conductive inks, printing technologies, and sintering processes, have been developed and are being actively studied.

Conventionally, nanomaterial-based conductive inks made with noble metals (such as Au and Ag) have been used in printed electronics because of their excellent conductivity, stability, and sintering efficiency under conventional processing conditions. However, these noble metals are not suitable for mass-production due to their high cost. For this reason, copper nanoparticle inks have received much attention as a low-cost substitute for silver or gold nanoparticles inks. ${ }^{4}$ However, copper nanoparticles (NPs) are easily oxidized in air, which results in a decrease in the electrical conductivity of $\mathrm{Cu}$ films. Thus, reduction of the oxide shell on the surface of the Cu NPs during sintering is necessary for obtaining highly conductive $\mathrm{Cu}$ films. It was also necessary to sinter $\mathrm{Cu}$ NPs at low temperature because $\mathrm{Cu}$ NPs are easily oxidized at high temperature under ambient conditions. Laser $^{5-7}$ and microwave $\mathrm{e}^{\mathbf{8 , 9}}$ sintering methods have been studied to solve these problems. However, these methods have limitations in mass-production

${ }^{a}$ Department of Mechanical Convergence Engineering, Hanyang University, Haengdang-dong, Seongdong-gu, Seoul 166-791, South Korea. E-mail: kima@ hanyang.ac.kr; Fax: +82-2220-2299; Tel: +82-2-2220-2898

${ }^{b}$ Institute of Nano Science and Technology, Hanyang University, Seoul, 133-791, Korea $\dagger$ Electronic supplementary information (ESI) available. See DOI: 10.1039/c7ra01429e because of their complexity and environmental restrictions (e.g., vacuum pressures). Moreover, they are not suitable for sintering large areas. Therefore, a new sintering technique enabling low temperature and rapid large area sintering is needed for the commercialization of flexible printed electronic devices.

We previously developed a flash light sintering process combined with PVP functionalized Cu NP-inks to overcome the limitations mentioned above. ${ }^{\mathbf{1 0 - 1 2}}$ Flash light sintering can reduce the copper oxide shell and sinter copper nanoparticles at room temperature under ambient conditions in just a few milliseconds without damaging the substrate. In addition, a flash light from a xenon lamp allows sintering of a large area. However, an in-depth study of the effect of copper oxide shell thickness on the flash light sintering of the Cu NP-ink has not yet been conducted.

Therefore, we investigated the effect of copper oxide shell thickness on the flash light sintering of Cu NPs in this study. $\mathrm{Cu}$ NPs covered with copper oxide shells that were $0.8 \mathrm{~nm}$ to $14 \mathrm{~nm}$ in thickness were prepared by heating to $25-500{ }^{\circ} \mathrm{C}$ in air. The prepared $\mathrm{Cu}$ NPs were sintered by flash light irradiation with various energy densities from $7.5 \mathrm{~J} \mathrm{~cm}^{-2}$ to $12.5 \mathrm{~J} \mathrm{~cm}^{-2}$. The amount of PVP in the $\mathrm{Cu}$ NP-ink was optimized with respect to the thickness of the oxide shell to enhance the reduction and sintering of the $\mathrm{Cu}$ NPs with a thick oxide shell. Furthermore, the number of pulse flashes was varied to efficiently reduce thick copper oxide shells without rapid volume contraction.

The thickness of the copper oxide-shell was measured using transmission electron microscopy (TEM), and the microstructures of the sintered $\mathrm{Cu}$ film were observed using scanning electron microscopy (SEM). Crystal phase analysis using X-ray diffraction (XRD) was performed to study the chemical shift of the copper nanoparticles. The sheet resistances of the $\mathrm{Cu}$ film were measured in real-time using an in-house resistance 
measurement system to investigate the reduction and sintering phenomena of the copper nanoparticles with respect to the copper oxide shell thickness.

\section{Materials and methods}

\subsection{Specimen preparation}

Commercially available $\mathrm{Cu}$ nanoparticles with an oxide shell (20-50 nm in diameter, copper(II) oxide shell; QSI-nano) were used in this study. Cu NPs with various oxide shells were prepared by heating at different temperatures using a forced convection oven for 2 hours (Table 1). To oxidize copper nanoparticles uniformly, $\mathrm{Cu}$ NPs were evenly spread on a plate. The prepared $\mathrm{Cu}$ NPs $(11.4 \mathrm{~g})$ were dispersed in a mixed solvent of diethylene glycol (DEG, 99\%; Samchun Chemical) (6 g) and poly( $N$-vinylpyrrolidone) (PVP, MW 40 000; Sigma Aldrich) (0.9$1.0 \mathrm{~g}$ ) using a three-roll mill. The amount of PVP was fixed at $0.9 \mathrm{~g}$ in order to observe how sintering changes with the thickness of the copper oxide shell. The amount of PVP was varied from 0.9 to $1.0 \mathrm{~g}$ with intervals of $0.025 \mathrm{~g}$ to optimize PVP content in the flash light sintering process. The fabricated $\mathrm{Cu}$ NP-inks were printed on a polyimide (PI) substrate using a doctor blade method and were dried on a hot plate $\left(100^{\circ} \mathrm{C}\right)$ for $3 \mathrm{~h}$.

\subsection{Flash light sintering and in situ monitoring of Cu NP-ink}

The printed $\mathrm{Cu}$ NP-inks were sintered by flash light irradiation at room temperature and ambient conditions. The flash light sintering system consisted of a xenon lamp (Perkin-Elmer Co,), a power supply (PSTek Co.), capacitors, a pulse controller, and a reflector (Semisysco Co) (Fig. 1). The white light from the xenon lamp has a broad wavelength range from 380 to $950 \mathrm{~nm}$. $\mathrm{Cu}$ NP-ink films were placed at a distance of $3 \mathrm{~mm}$ from the lamp and the irradiation energy was varied from $7.5 \mathrm{~J} \mathrm{~cm}^{-2}$ to $12.5 \mathrm{~J} \mathrm{~cm}^{-2}$. In order to observe the thickness effect of the copper oxide shell, the number of pulses, on-time, and off-time were fixed at the optimized values from the previous study results. ${ }^{13}$

In order to monitor the sintering process in real time, the change in the resistance of the Cu NP-ink films over a period of a few milliseconds was measured using a Wheatstone bridge electrical circuit, a source meter (2611A; Keithley), and an oscilloscope (DL1740E; Yokogawa).

Table 1 Thickness of copper oxide shell depending on heating temperature

\begin{tabular}{lll}
\hline $\begin{array}{l}\text { Acronym of copper } \\
\text { nanoparticles }\end{array}$ & $\begin{array}{l}\text { Heating temperature } \\
\text { (during } 2 \text { hours) }\end{array}$ & $\begin{array}{l}\text { Thickness of } \\
\text { copper oxide shell }\end{array}$ \\
\hline Cu NPs-RT & $25{ }^{\circ} \mathrm{C}$ & $0.8 \mathrm{~nm}$ \\
Cu NPs-100 & $100{ }^{\circ} \mathrm{C}$ & $2.1 \mathrm{~nm}$ \\
Cu NPs-200 & $200{ }^{\circ} \mathrm{C}$ & $3.6 \mathrm{~nm}$ \\
Cu NPs-300 & $300{ }^{\circ} \mathrm{C}$ & $7.1 \mathrm{~nm}$ \\
Cu NPs-400 & $400{ }^{\circ} \mathrm{C}$ & $12.6 \mathrm{~nm}$ \\
Cu NPs-500 & $500^{\circ} \mathrm{C}$ & $14.0 \mathrm{~nm}$
\end{tabular}

(a)

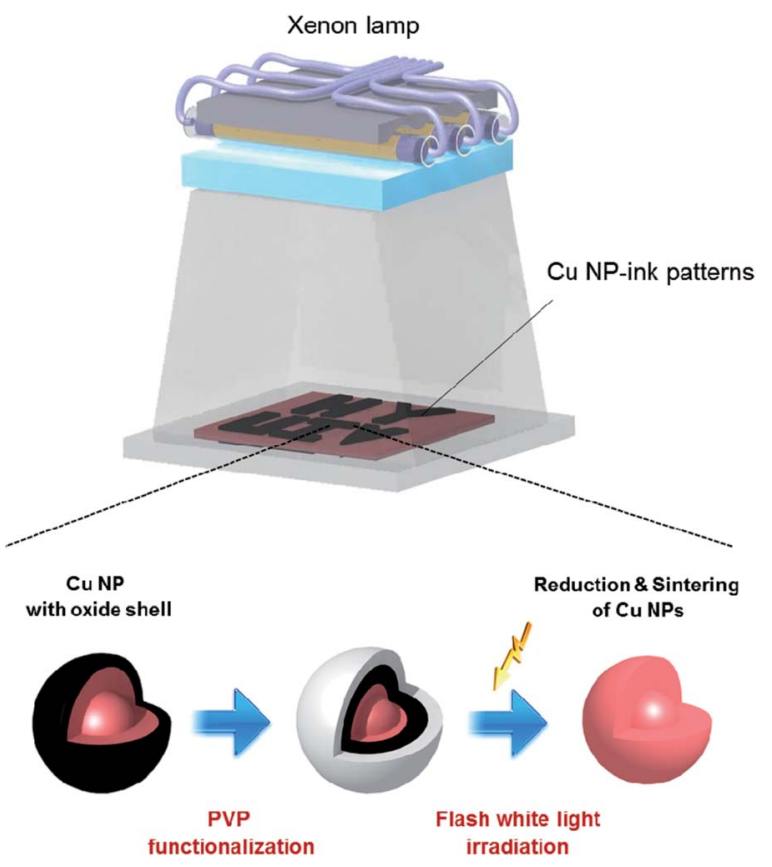

Fig. 1 Schematics of the photonic sintering process of Cu NP-ink with copper oxide shell using flash white light.

\subsection{Characterization}

The thickness of the copper oxide-shell was measured using transmission electron microscopy (TEM, JEM-2100F) and the microstructures and surfaces of the sintered $\mathrm{Cu}$ film were observed using scanning electron microscopy (SEM, S4800 Hitachi). Crystal phase analysis was performed using X-ray diffractometry (XRD, D/MAX RINT 2000, $\mathrm{Cu} \mathrm{K \alpha}$ radiation) to investigate the oxidation or reduction of the oxide. The electrical sheet resistances of the $\mathrm{Cu}$ nanofilms were measured using a four-point probe method.

\section{Results and discussion}

HR-TEM was used to evaluate the oxide shells of the $\mathrm{Cu}$ nanoparticles (NPs). Cu NPs used in this study were manufactured using a vapor condensation process, which resulted in a copper(II) oxide (CUO) shell on the surface of the nanoparticles for passivation. ${ }^{\mathbf{1 4 , 1 5}}$ For this reason, a copper oxide shell that was $0.8 \mathrm{~nm}$ thickness was observed even for the non-treated copper nanoparticles (Fig. 2a). It was also observed that the thickness of the copper oxide shell increased from $2.1 \mathrm{~nm}$ to $14 \mathrm{~nm}$ as the oxidation temperature increased from $100{ }^{\circ} \mathrm{C}$ to $500{ }^{\circ} \mathrm{C}$ (Fig. $2 \mathrm{~b}-$ f) and these values were determined through averaging that based on various TEM images (Fig. S1a-f $\dagger$ ). This is because $\mathrm{Cu}$ nanoparticles were easily oxidized in the air, and high temperature accelerated the oxidation. ${ }^{16}$

XRD patterns shown in Fig. 3b demonstrated that pure copper phase peaks $\left(43.2^{\circ}, 50.4^{\circ}\right.$ and $\left.74.1^{\circ}\right)$ decreased and copper(I) oxide $\left(\mathrm{Cu}_{2} \mathrm{O}\right)$ peaks $\left(36.4^{\circ}\right.$ and $\left.38^{\circ}\right)$ increased as the oxidation temperature increased. ${ }^{17}$ This means that higher temperature caused significant oxidation of pure copper in air 

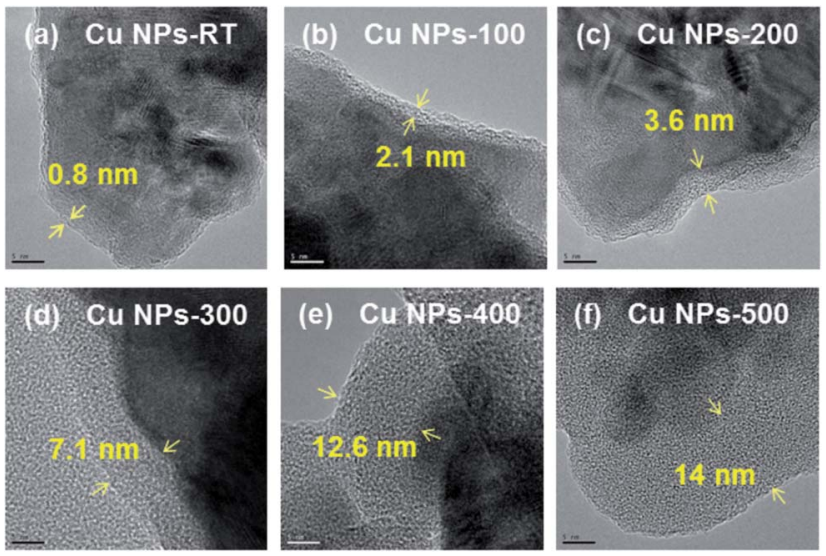

(g)
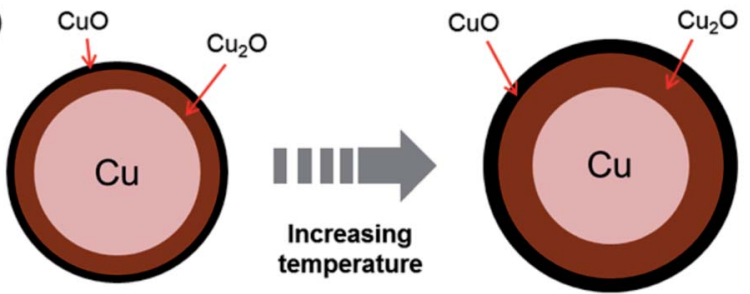

Fig. 2 HR-TEM images of (a) Cu NPs-RT, (b) Cu NPs-100, (c) Cu NPs200, (d) Cu NPs-300, (e) Cu NPs-400, (f) Cu NPs-500 and (g) schematic illustration of the surface composition change of $\mathrm{Cu}$ NPs.

as shown in eqn (1), which produces a thicker copper oxide shell $\left(\mathrm{Cu}_{2} \mathrm{O}\right)$. When the temperature was higher than $300{ }^{\circ} \mathrm{C}$, the peaks associated with copper(II) oxide $\left(35.5^{\circ}\right.$ and $\left.38.7^{\circ}\right)$ remarkably increased and pure $\mathrm{Cu}$ phase peaks $\left(43.2^{\circ}, 50.4^{\circ}\right.$ and $74.1^{\circ}$ ) were difficult to observe because the copper(I) oxide shell on the surface of the Cu NPs was further oxidized eqn (2), resulting in thick $\mathrm{Cu}$ oxide shells.

$$
4 \mathrm{Cu}+\mathrm{O}_{2} \rightarrow 2 \mathrm{Cu}_{2} \mathrm{O}
$$

$$
2 \mathrm{Cu}_{2} \mathrm{O}+\mathrm{O}_{2} \rightarrow 4 \mathrm{CuO}
$$

Key data from the characterization of $\mathrm{Cu}$ NPs are schematically illustrated in Fig. 2g. Cu NPs were oxidized under ambient atmospheric conditions to form a surface oxide composed of $\mathrm{Cu}_{2} \mathrm{O}$ (detected by FTIR and XRD), which was covered with a thin outer layer of $\mathrm{CuO}$ (XPS, XRD, and FTIR). ${ }^{18}$ The temperature of the atmosphere played a significant role. Specifically, a $\mathrm{Cu}_{2} \mathrm{O}$ layer was formed on the surface of the $\mathrm{Cu}$ NPs below $100{ }^{\circ} \mathrm{C}$, while a complex oxide of $\mathrm{Cu}_{3} \mathrm{O}_{2}$ formed at about $150{ }^{\circ} \mathrm{C}$. A thin layer of $\mathrm{CuO}$ formed on the outer layer at temperatures above $200{ }^{\circ} \mathrm{C}$. Thus, the compounds observed during formation of a $\mathrm{Cu}$ oxide shell $\left(\mathrm{Cu}_{x} \mathrm{O}\right)$ followed the order $\mathrm{Cu}_{2} \mathrm{O}, \mathrm{Cu}_{3} \mathrm{O}_{2}$, and $\mathrm{CuO}$ with increasing temperature; eventually, all oxides coexisted on the surface. ${ }^{19-21}$ The results of XRD (Fig. 3b) are in agreement with these results from previous studies. The copper(II) oxide (CuO) peaks were observed even in the non-heated $\mathrm{Cu}$ nanoparticles (Cu NPs-RT) (see the black line in Fig. 3b), and these were derived from the synthesis process of $\mathrm{Cu}$ NPs.

To reduce and sinter the $\mathrm{Cu}$ NPs with a copper oxide shell, we functionalized the Cu NPs with PVP (Cu NPs: $11.4 \mathrm{~g}$, PVP: $0.9 \mathrm{~g}$ ) and varied the irradiation energy of the flash light from $7.5 \mathrm{~J}$ $\mathrm{cm}^{-2}$ to $12.5 \mathrm{~J} \mathrm{~cm}^{-2}$; one pulse of flash light with a duration of 10 ms was used, based on our previous study. ${ }^{13}$ As shown in Fig. 3a, the resistivity of the Cu NP-ink films decreased as the irradiation energy increased up to $12.5 \mathrm{~J} \mathrm{~cm}^{-2}$. These results are consistent with those reported in our previous studies. ${ }^{13}$ The PVP layer decomposed and evaporated after flash light irradiation, allowing the copper oxide shell to be reduced. The copper nanoparticles were simultaneously sintered by the flash light, resulting in a decrease in resistivity. However, it was found that $\mathrm{Cu}$ NPs with thicker oxide shells had a higher resistivity after flash light sintering (Fig. 3a). This may be because $\mathrm{Cu}$ oxide shells disturbed the sintering of $\mathrm{Cu}$ NPs during flash light irradiation. XRD patterns shown in Fig. $3 \mathrm{c}$ demonstrated that pure copper (a)

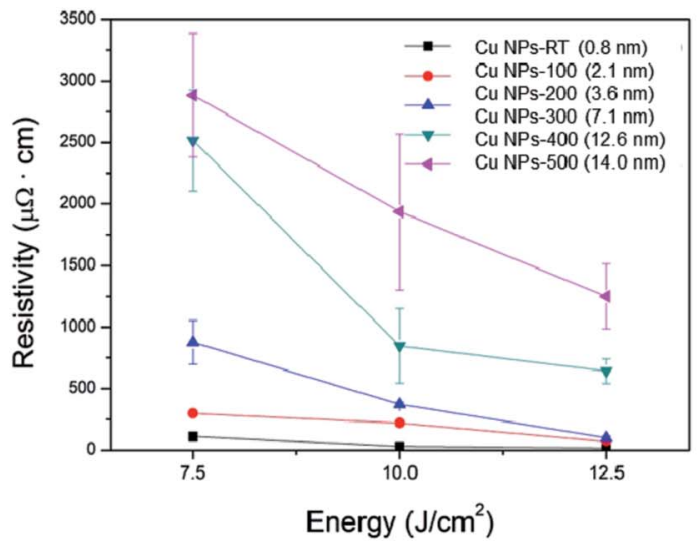

(b)

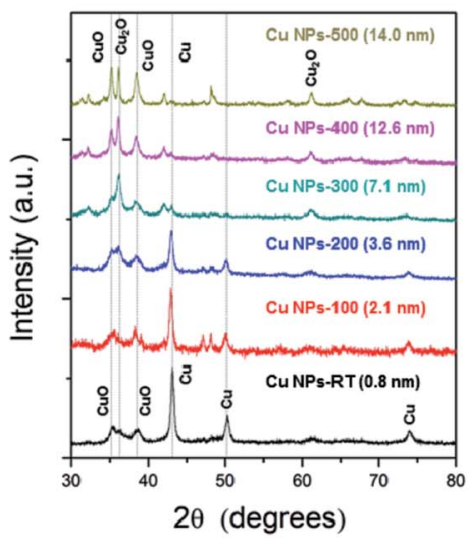

(c) After flash-light sintering

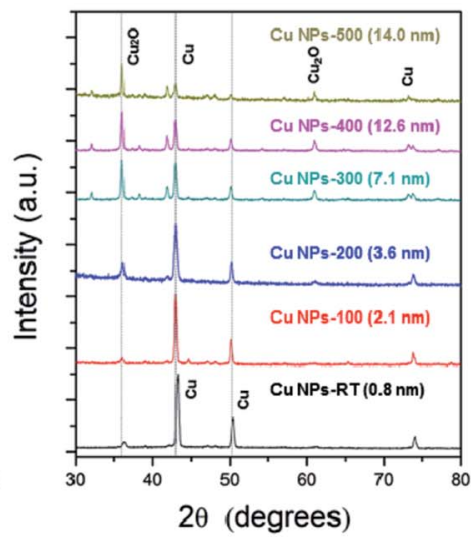

Fig. 3 Flash light sintering of Cu NP-ink with different oxide-shell. (a) The resistivity of the flash light sintered Cu nano-ink films as increasing the irradiation energy from $7.5 \mathrm{~J} \mathrm{~cm}^{-2}$ to $12.5 \mathrm{~J} \mathrm{~cm}^{-2}$ (single pulse with pulse duration of $10 \mathrm{~ms}$ ). XRD patterns of the (b) unsintered and (c) flash lightsintered of Cu nano-ink films with different oxide shell thickness (irradiation energy: $12.5 \mathrm{~J} \mathrm{~cm}^{-2}$, pulse duration: $10 \mathrm{~ms}$, pulse number: 1 ). 
phase peaks $\left(43.2^{\circ}, 50.4^{\circ}\right.$ and $\left.74.1^{\circ}\right)$ decreased as the thickness of the oxide shell increased, although the intensity of the pure $\mathrm{Cu}$ phase peaks increased and the peaks of the $\mathrm{Cu}$ oxide ( $\mathrm{CuO}$ and $\mathrm{Cu}_{2} \mathrm{O}$ ) decreased after flash light irradiation. Therefore, it could be concluded that the copper oxide shell disturbs the sintering of the $\mathrm{Cu}$ NPs. The peaks associated with copper(II) oxide (CuO) were entirely removed for all cases after flash light sintering (Fig. 3c). This indicates that copper(II) oxide (CuO) was reduced to pure copper by $\mathrm{OH}$ radicals derived from $\mathrm{PVP}$ decomposition through flash light irradiation according to eqn (3).22,23

$$
\begin{gathered}
\mathrm{CuO}+2 \mathrm{OH} \rightarrow \mathrm{Cu}+\mathrm{H}_{2} \mathrm{O}+\mathrm{O}_{2} \\
2 \mathrm{CuO}+2 \mathrm{OH} \rightarrow \mathrm{Cu}_{2} \mathrm{O}+\mathrm{H}_{2} \mathrm{O}+\mathrm{O}_{2}
\end{gathered}
$$

However, when the oxidation temperature was higher than $300{ }^{\circ} \mathrm{C}$, peaks associated with copper $(\mathrm{I})$ oxide $\left(\mathrm{Cu}_{2} \mathrm{O}\right)$ remained even after flash light sintering. Thus, $\mathrm{Cu}$ oxide shells thicker than $7.1 \mathrm{~nm}\left(>300^{\circ} \mathrm{C}\right)$ were not reduced fully due to a lack of $\mathrm{OH}$ radicals from PVP chains, resulting in residual copper(I) oxide $\left(\mathrm{Cu}_{2} \mathrm{O}\right)$ eqn (4). Moreover, the thick oxide shell caused agglomeration in $\mathrm{Cu}$ NPs as shown in Fig. S2a-c† because hydrophilic copper oxide enhanced the agglomeration of NPS due to their highly polar nature. ${ }^{24,25}$ The agglomeration of NPs reduced the surface area for PVP adhesion, resulting in an incomplete reduction of $\mathrm{Cu}$ oxide and a low uniformity in the $\mathrm{Cu}$ NP-ink films (Fig. S2d $\dagger$ ). For these reasons, the resistivity of the sintered $\mathrm{Cu}$ NPs-300, 400 and 500 with oxide shells thicker than $7.1 \mathrm{~nm}\left(>300{ }^{\circ} \mathrm{C}\right)$ dramatically increased (Fig. 3a).

In order to investigate the reduction of the oxide shell and flash light sintering mechanism of $\mathrm{Cu}$ NPs, a Wheatstone bridge electrical circuit and an oscilloscope were used to monitor the sintering process of $\mathrm{Cu}$ NP-ink (PVP weigh fraction: $7.3 \%$ ) in real time under optimum irradiation energy conditions (irradiation energy of $12.5 \mathrm{~J} \mathrm{~cm}^{-2}$, pulse number of 1 , pulse duration of $10 \mathrm{~ms}$ ) (Fig. 4). It was observed that the electrical resistance of the Cu NPs-1 ink film decreased to about $3.7 \Omega \mathrm{sq}^{-1}$ immediately after flash light irradiation (Fig. 4a). In this period, the $\mathrm{Cu}$ oxide shell surrounding the Cu NPs might be reduced via decomposition of the PVP coating layer and sintered by flash light irradiation. However, we found that the decrease in the resistance during flash light irradiation was restricted as the oxidation temperature increased (Fig. 4b-e). Moreover, when the $\mathrm{Cu}$ oxide shell was thicker than $2.1 \mathrm{~nm}$, the sheet resistance increased again during flash light irradiation. This may be because the $\mathrm{Cu}$ oxide was not reduced fully and $\mathrm{Cu}$ NPs were reoxidized during flash light irradiation due to a lack of PVP chains, resulting in more inter-granular pores as shown in the SEM images (see insets in Fig. 4b-e). Also, when the oxidation temperature was higher than $400{ }^{\circ} \mathrm{C}$, the sintered $\mathrm{Cu} \mathrm{NP}$ films had an island-like film surface (Fig. 4e) because of the agglomeration of $\mathrm{Cu}$ NPs with a thick oxide shell. These results corresponded to the previous electrical resistivity and XRD results (Fig. 3). Hwang et al. demonstrated that the PVP amount for a complete reduction of copper oxide is linearly proportional to the amount of copper oxide shell. ${ }^{13}$ Therefore, it was necessary to optimize the amount of PVP with respect to the thickness of the $\mathrm{Cu}$ oxide shell to enhance the reduction of the $\mathrm{Cu}$ oxide shell and improve the electrical resistivity.

The optimal amount of PVP in Cu NP-RT ink was previously determined to be $7.3 \mathrm{wt} \%$ (0.9 g PVP and $11.4 \mathrm{~g} \mathrm{Cu} \mathrm{NPs)} \mathrm{to}$ ensure the full-reduction of a thin $\mathrm{Cu}$ oxide shell (thickness of $0.8 \mathrm{~nm}) .{ }^{13}$ To fully reduce thick $\mathrm{Cu}$ oxide shells, the amount of PVP was increased to $1.0 \mathrm{~g}$. As shown in Fig. 5a-c, inks of $\mathrm{Cu}$ (a)
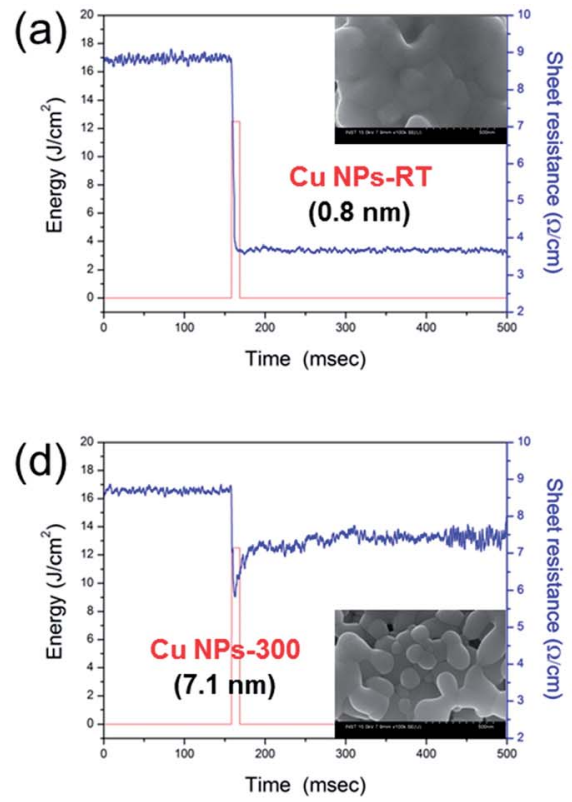

(b)

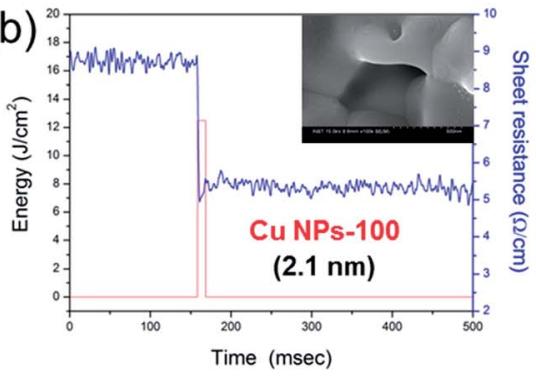

(e)

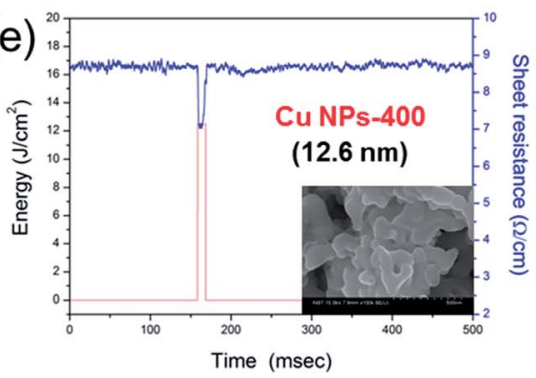

Fig. 4 In situ monitoring of sheet resistance change of Cu films during the flash light sintering process (irradiation energy: $12.5 \mathrm{~J} \mathrm{~cm}^{-2}$, pulse duration: 10 ms, pulse number: 1). (a) Cu NPs-RT, (b) Cu NPs-100, (c) Cu NPs-200, (d) Cu NPs-300, and (e) Cu NPs-400 (inset: SEM images of the Cu nano-ink sintered by flash light). 
NPs-100, 200 and 300 showed the lowest electrical resistivity when the amount of PVP was $0.900 \mathrm{~g}, 0.925 \mathrm{~g}$, and $0.950 \mathrm{~g}$, respectively. As shown in the XRD patterns, we also observed that the copper(II) oxide $(\mathrm{CuO})$ phase peaks $\left(35.5^{\circ}\right.$ and $\left.38.7^{\circ}\right)$ disappeared completely and copper(I) oxide $\left(\mathrm{Cu}_{2} \mathrm{O}\right)$ phase peaks $\left(36.4^{\circ}\right)$ decreased, while pure $\mathrm{Cu}$ phase peaks $\left(43.2^{\circ}, 50.4^{\circ}\right.$, and $74.1^{\circ}$ ) increased after the optimization of PVP amount (Fig. $5 \mathrm{~d}-$ f). This is because the amount of PVP was sufficient to efficiently reduce the $\mathrm{Cu}$ oxide shells, resulting in a lower porosity and more connections among the nanoparticles compared to cases with less PVP and the worst resistivity (see inset SEM images in Fig. 5d-f). Optimization of the amount of PVP with respect to the thickness of the oxide shell resulted in an enhanced reduction of $\mathrm{Cu}$ oxide and improved sintering of $\mathrm{Cu}$ NPs, which reduced the electrical resistivity of the sintered $\mathrm{Cu}$ films. However, when the $\mathrm{Cu}$ oxide shell thickness was $7.1 \mathrm{~nm}$, the resistivity of the sintered $\mathrm{Cu}$ film was still high (about $450 \mu \Omega$ $\mathrm{cm}$ ) even after the amount of PVP was optimized. Moreover, when the $\mathrm{Cu}$ oxide shell thickness was thicker than $12.6 \mathrm{~nm}$, more PVP functionalization caused damage in the $\mathrm{Cu}$ films after flash light irradiation, as shown in Fig. 5g. Thicker layers of PVP and $\mathrm{Cu}$ oxide shells disrupted the light absorption and the sintering of $\mathrm{Cu}$ NPs and caused delamination of $\mathrm{Cu}$ films due to the residual layers of PVP and $\mathrm{Cu}$ oxide on the Cu NPs. Therefore, it was concluded that Cu NPs with oxide shells thicker than $10 \mathrm{~nm}$ were not suitable for the flash light sintering process. $\mathrm{Cu}$ NPs with oxide shells less than $7 \mathrm{~nm}$ thick were necessary for fabricating highly conductive $\mathrm{Cu}$ NP-inks.
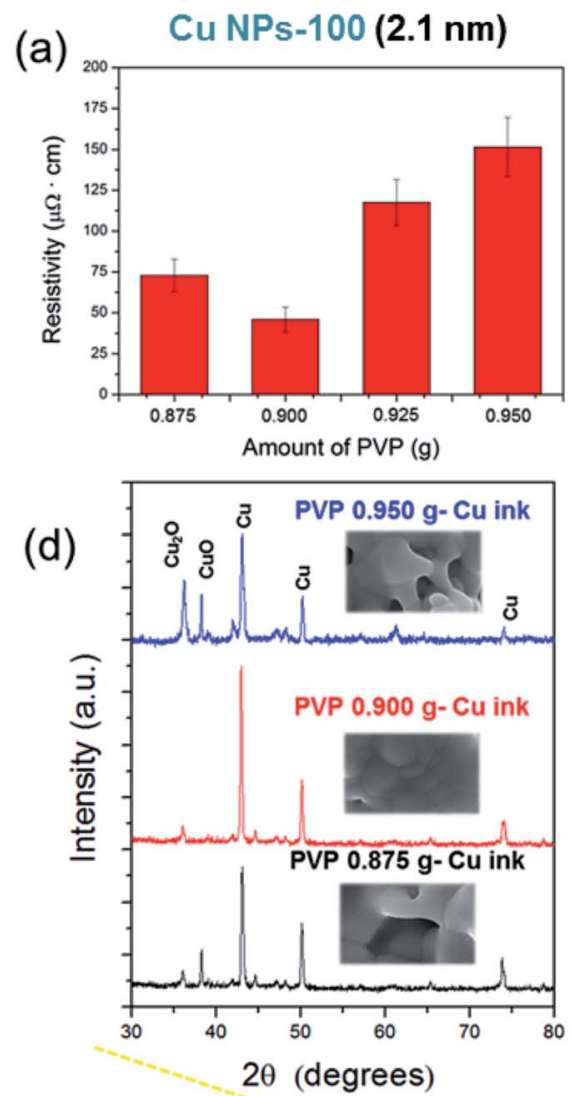
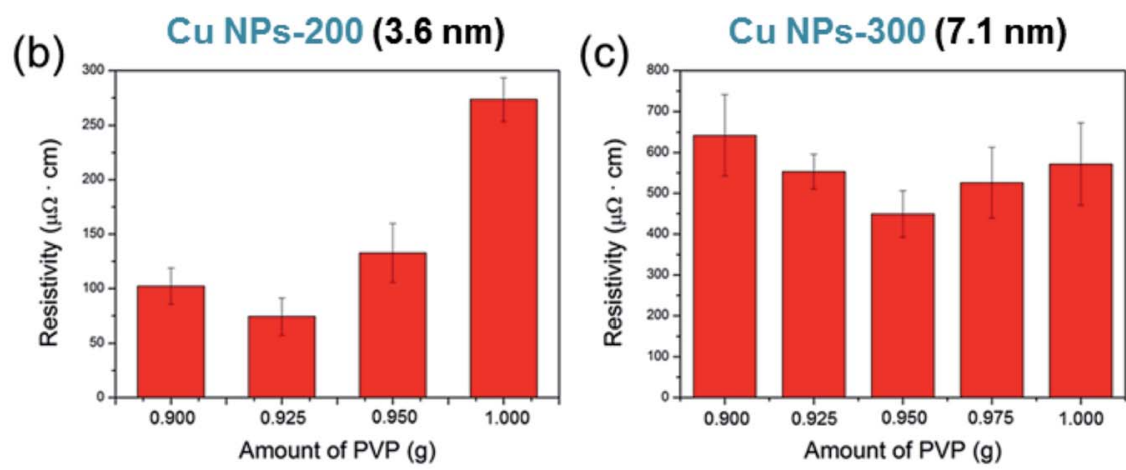

(e)
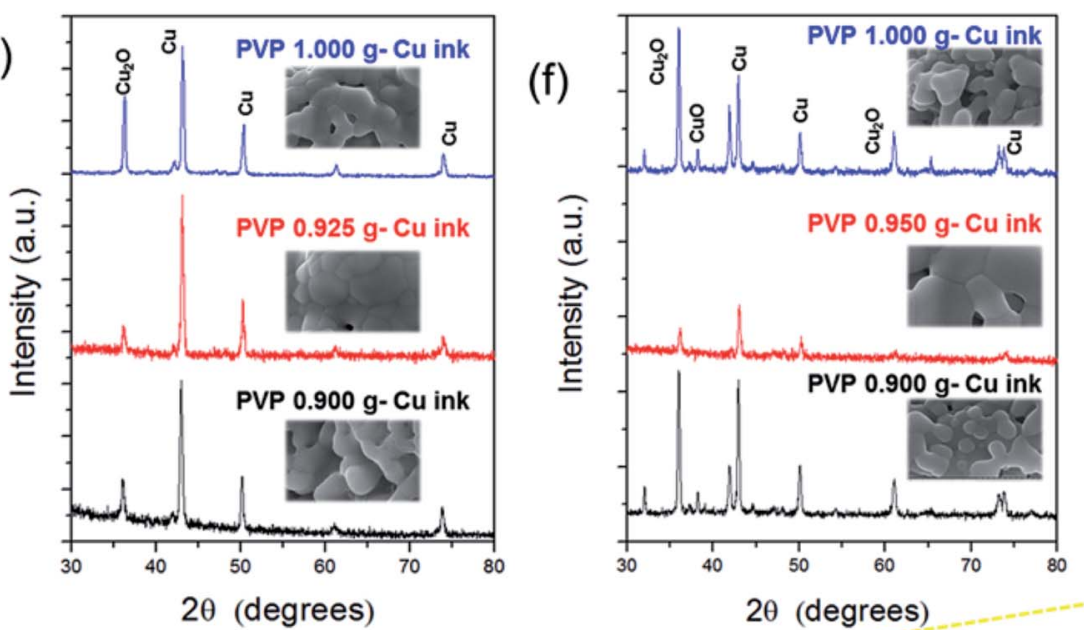

(g)

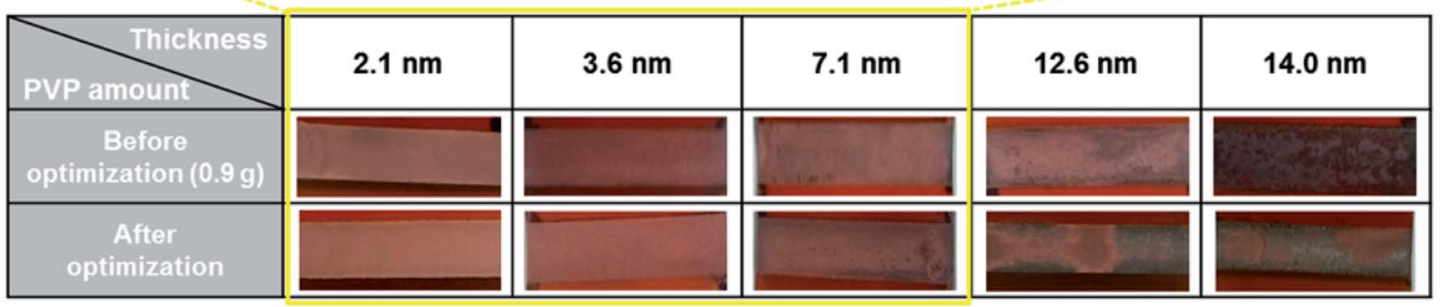

Fig. 5 Optimization of PVP amount for reducing and sintering of Cu NP-ink with different oxide-shell thickness. (a-c) The resistivity of Cu nanoink films with different amount of PVP with respect to the thickness of Cu oxide shell. ( $d-f)$ XRD patterns of the flash light-sintered Cu nano-ink films before- (black line) and after- (red line) optimization of PVP amount (irradiation energy: $12.5 \mathrm{~J} \mathrm{~cm}^{-2}$, pulse duration: $10 \mathrm{~ms}$, pulse number: 1 ). (g) Optical images of the optimally PVP functionalized Cu nano-ink films after flash light sintering (irradiation energy: $12.5 \mathrm{~J} \mathrm{~cm}{ }^{-2}$, pulse duration: $10 \mathrm{~ms}$, pulse number: 1). 
It was also found that the Cu NP-200 ink still had a high resistivity (Fig. 5b), and the copper(I) oxide $\left(\mathrm{Cu}_{2} \mathrm{O}\right)$ phase peak $\left(36.4^{\circ}\right)$ still remained in this sample even after optimization of the amount of PVP (Fig. 5e). This may because the PVP layers were not decomposed entirely by flash light with a single pulse because they were quite heavy. Incomplete decomposition of PVP resulted in an incomplete reduction of the $\mathrm{Cu}$ oxide shell (Fig. 6a). To resolve these problems, multiple pulses (irradiation energy per pulse of $2 \mathrm{~J} \mathrm{~cm}^{-2}$, pulse duration of $3 \mathrm{~ms}$, and pulse gap of $3 \mathrm{~ms}$ ) were applied with an increasing number of pulses from 4 to 10. It was noteworthy that the resistivity of the $\mathrm{Cu}$ films decreased as the pulse number increased up to 7 (Fig. 6b). This was because a thick $\mathrm{Cu}$ oxide shell was gradually reduced with PVP decomposition, and Cu NPs were increasingly sintered as the number of pulses increased (Fig. 6a). To investigate the gradual reduction and sintering process, the sheet resistance change observed in a $\mathrm{Cu}$ film was monitored during multipulsed flash light irradiation in real time (Fig. 6c). The sheet resistance of the $\mathrm{Cu}$ films decreased incrementally after each flash light pulse irradiation. The sheet resistance decreased significantly after the first and the second pulses, followed by less significant decreases after the following pulses. Finally, the sheet resistance stabilized at its final value $\left(4.2 \Omega \mathrm{sq}^{-1}\right)$ after the seventh pulse. Both the reduction of the $\mathrm{Cu}$ oxide shell and sintering of $\mathrm{Cu}$ NPs continued during pulse irradiation up to the seventh pulse. However, the resistivity increased again when more than 7 pulses were used because Cu NPs were re-oxidized due to the excessive irradiation energy (Fig. 6b). We also found that $0.925 \mathrm{~g}$ of PVP produced a higher conductivity than any other PVP amount (Fig. 6b), which was in agreement with the results of the PVP optimization (Fig. 5).

Fig. 7a shows a comparison of the resistivity of the Cu NP-200 (3.6 nm thick oxide shell) films sintered by flash light. As shown, the Cu NP-200 ink functionalized by $0.925 \mathrm{~g}$ of PVP had smaller pore sizes and more connections among the nanoparticles than those of the $0.900 \mathrm{~g}$ PVP case, which resulted in a decrease in the electrical resistivity $(-27.6 \%)$. This was because the higher amount of PVP more effectively reduced the thick $\mathrm{Cu}$ oxide shells. Meanwhile, the lowest resistivity $\mathrm{Cu}$ film was obtained using multiple flash light irradiations. The XRD pattern of the optimal PVP functionalized (PVP of $0.925 \mathrm{~g}$ ) and sintered (pulse number of 7, irradiation energy per pulse of $2 \mathrm{~J} \mathrm{~cm}^{-2}, 3 \mathrm{~ms}$ pulse duration, and $3 \mathrm{~ms}$ pulse gap) Cu NP-200 ink showed a pure $\mathrm{Cu}$ peak $\left(43.2^{\circ}\right)$ with less $\mathrm{Cu}$ oxide $\left(36.4^{\circ}\right)$ due to further reduction of the $\mathrm{Cu}$ oxide shells and crystallization of the pure $\mathrm{Cu}$ phase (Fig. 7b) and the peak ratios of $\mathrm{Cu}$ oxide peak $\left(36.4^{\circ}\right)$ to pure $\mathrm{Cu}$ peak $\left(43.2^{\circ}\right)$ were $0.4020,0.2888$ and 0.1182 in cases of single pulse with $0.900 \mathrm{~g}$ PVP, single pulse with $0.925 \mathrm{~g}$ PVP and multiple pulse with $0.925 \mathrm{~g}$, respectively (Fig. 7c). Furthermore, as shown in the inset SEM image in Fig. 7a, the optimized conductive $\mathrm{Cu}$ film had a larger grain size and a resistivity of $43.83 \mu \Omega \mathrm{cm}$, which was $57.1 \%$ lower than that obtained from a single pulse with $0.900 \mathrm{~g}$ PVP. Therefore, it was demonstrated that multi-pulsed flash light irradiation enhanced the reduction and sintering of $\mathrm{Cu}$ NPs with thick $\mathrm{Cu}$ oxide shells and PVP layers.

Multiple pulses reduced and sintered the thick $\mathrm{Cu}$ oxide shell more effectively without an abrupt volume contraction as

(a)
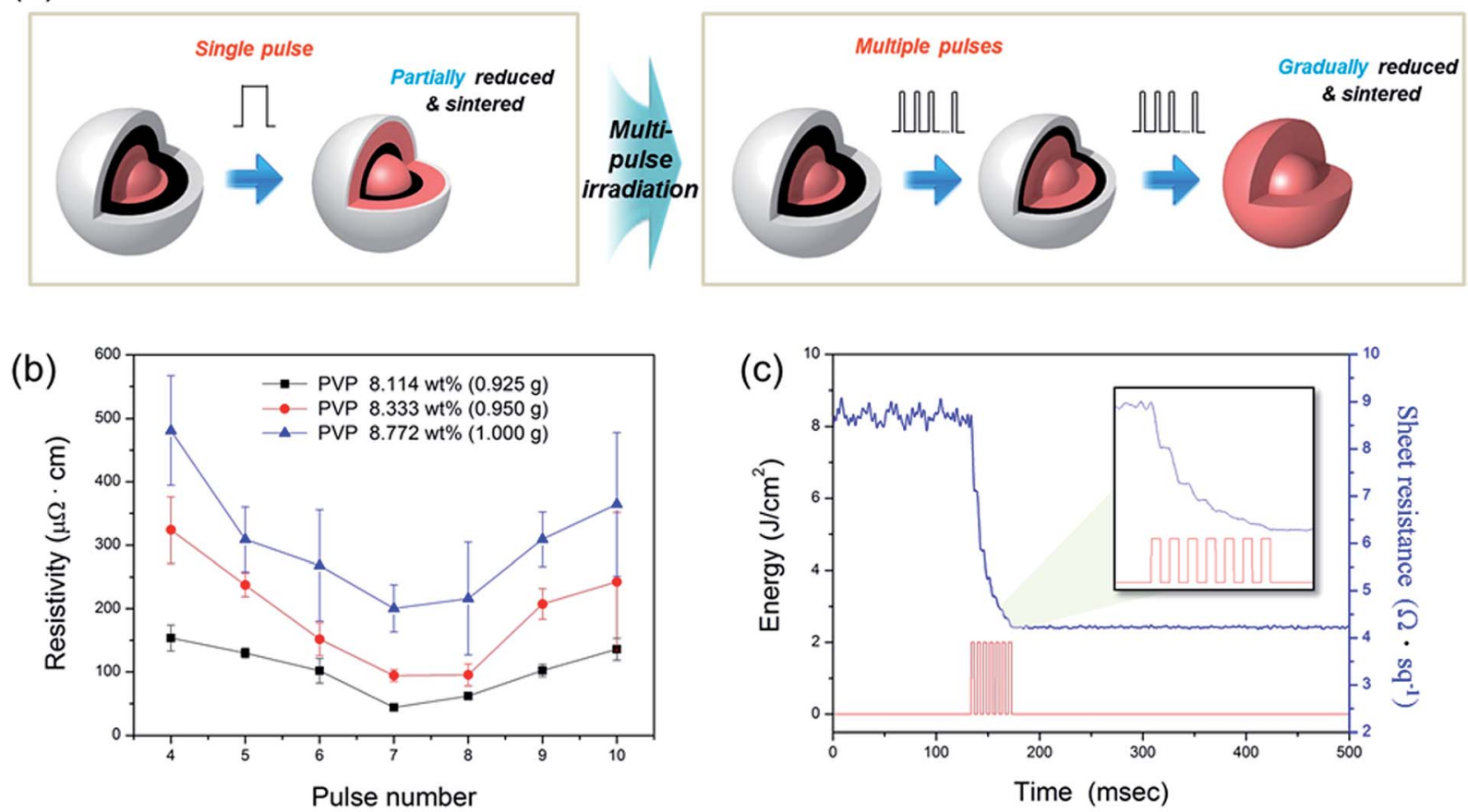

Fig. 6 (a) Schematic of single and multiple pulsed flash light sintering processes for Cu NPs-200 ink (thickness of oxide shell: 3.6 nm). (b) The resistivity of the flash light sintered Cu nano-ink films as increasing the number of pulse from 4 to 10 (a pulse energy: $2 \mathrm{~J} \mathrm{~cm}^{-2}$, pulse duration: 3 $\mathrm{ms}$, and pulse gap: $3 \mathrm{~ms}$ ). (c) In situ monitoring of sheet resistance change of Cu films during the flash light sintering process. 
(a)

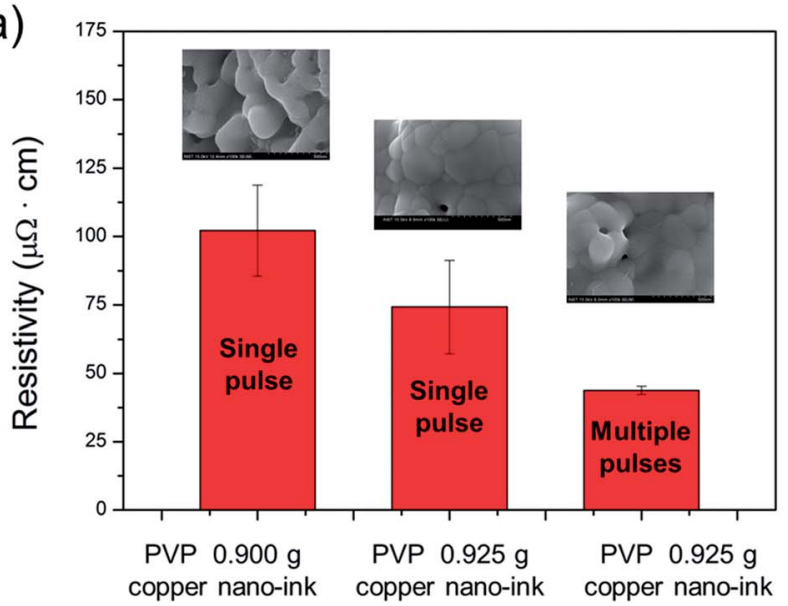

(b)

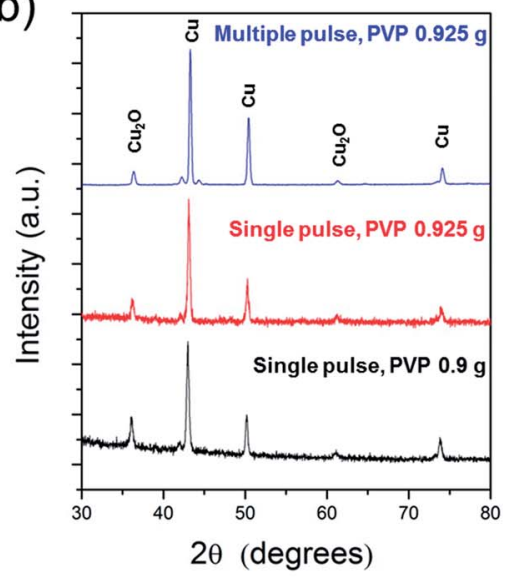

(c)

\begin{tabular}{c|c|c|c}
\hline Pulse mode & Single & Single & Multiple \\
\hline Amount of PVP & $0.900 \mathrm{~g}$ & $0.925 \mathrm{~g}$ & $0.925 \mathrm{~g}$ \\
\hline $\begin{array}{c}\text { Peak ratio of } \\
\begin{array}{c}\text { Cu oxide peak }\left(36.4^{\circ}\right) \\
\text { to pure Cu peak }\left(43.2^{\circ}\right)\end{array}\end{array}$ & 0.4020 & 0.2888 & 0.1182 \\
\hline
\end{tabular}

Fig. 7 Comparison of the resistivity (a) and XRD patterns (b) of the PVP functionalized Cu NPs-200 ink films (3.6 nm thick oxide shell) sintered flash light and (c) peak ratio of Cu oxide peak $\left(36.4^{\circ}\right)$ to pure Cu peak $\left(43.2^{\circ}\right)$.

compared to single pulse processes. Unfortunately, however, the resistivity of the optimally sintered $\mathrm{Cu}$ film with a $3.6 \mathrm{~nm}$ thick oxide shell $(43.83 \mu \Omega \mathrm{cm})$ was still higher than that of the $\mathrm{Cu}$ film with a $0.8 \mathrm{~nm}$ thick oxide shell $(17.34 \mu \Omega \mathrm{cm})$. This is due to the thick $\mathrm{Cu}$ oxide shell on the surface of the Cu NPs, which inhibits light absorption and sintering of Cu NPs. Even though the resistivity of the $\mathrm{Cu}$ film was still high, it is a highly significant discovery that Cu NPs with thick oxide shells $(<7 \mathrm{~nm})$ can be sintered by flash light irradiation at room temperature under ambient conditions in just a few milliseconds without damaging the substrate.

\section{Conclusion}

In this work, the effect of the thickness of the copper oxide shell on the flash light sintering of $\mathrm{Cu}$ NPs was investigated. In addition, the amount of PVP functionalization was optimized with respect to the thickness of the copper oxide shell in order to enhance the reduction and sintering of Cu NPs with a thick oxide shell. It was found that PVP functionalization improved the reduction of thick $\mathrm{Cu}$ oxide shells. However, $\mathrm{Cu}$ NPs with oxide shells thicker than $7 \mathrm{~nm}$ were not suitable for the flash light sintering method, because they agglomerated and showed a low reduction rate even after optimization of the amount of PVP. Therefore, it was concluded that it is preferable to have a copper oxide shell that is less than $4 \mathrm{~nm}$ thick for the flash light sintering process. It was also noteworthy that multi-pulsed flash light irradiations could decompose thick PVP layers and reduce thicker $\mathrm{Cu}$ oxide shells effectively without damaging the $\mathrm{Cu}$ films. The optimally PVP functionalized and flash light sintered $\mathrm{Cu}$ film with a $3.6 \mathrm{~nm}$ oxide shell had a resistivity of $43.83 \mu \Omega \mathrm{cm}$, which was $57.1 \%$ lower than that of the non-optimized $\mathrm{Cu}$ film $(102.2 \mu \Omega \mathrm{cm})$. The novel photonic sintering technique for $\mathrm{Cu}$ NP-ink described here is a viable approach to realize room temperature in situ sintering of printed electronics.

\section{Acknowledgements}

This work was supported by a National Research Foundation of Korea (NRF), funded by the Ministry of Education (2015R1D1A1A09058418, 2012R1A6A1029029) and grant funded by the Korean Government (MEST) (2013M2A2A9043280). This work was also supported by the Technology Innovation Program (or Industrial Strategic Technology Development Program, 10048913, Development of the cheap nanoink, which is sintered in the air for smart devices) funded by the Ministry of Trade, Industry, \& Energy (MI, Korea).

\section{References}

1 J. Perelaer, A. W. De Laat, C. E. Hendriks and U. S. Schubert, J. Mater. Chem., 2008, 18, 3209-3215.

2 S. K. Volkman, Y. Pei, D. Redinger, S. Yin and V. Subramanian, MRS Online Proc. Libr., 2004, 814, DOI: 10.1557/PROC-814-I7.8.

3 Z. Liu, Y. Su and K. Varahramyan, Thin Solid Films, 2005, 478, 275-279.

4 D. Li, D. Sutton, A. Burgess, D. Graham and P. D. Calvert, J. Mater. Chem., 2009, 19, 3719-3724.

5 A. Simchi, Mater. Sci. Eng., 2006, 428, 148-158.

6 M. Zenou, O. Ermak, A. Saar and Z. Kotler, J. Phys. D: Appl. Phys., 2013, 47, 025501. 
7 H. Zhu, L. Lu and J. Fuh, J. Mater. Process. Technol., 2003, 140, 314-317.

8 D. Demirskyi, D. Agrawal and A. Ragulya, Mater. Lett., 2010, 64, 1433-1436.

9 C.-L. Huang, R.-J. Lin and J.-F. Tzeng, Mater. Chem. Phys., 2006, 97, 256-260.

10 Y.-T. Hwang, W.-H. Chung, Y.-R. Jang and H.-S. Kim, ACS Appl. Mater. Interfaces, 2016, 8, 8591-8599.

11 S.-J. Joo, H.-J. Hwang and H.-S. Kim, Nanotechnology, 2014, 25, 265601.

12 H.-S. Kim, S. R. Dhage, D.-E. Shim and H. T. Hahn, Appl. Phys. A: Mater. Sci. Process., 2009, 97, 791-798.

13 H.-J. Hwang, W.-H. Chung and H.-S. Kim, Nanotechnology, 2012, 23, 485205.

14 A. G. Nasibulin, P. P. Ahonen, O. Richard, E. I. Kauppinen and I. S. Altman, J. Nanopart. Res., 2001, 3, 383-398.

15 A. G. Nasibulin, E. I. Kauppinen, D. P. Brown and J. K. Jokiniemi, J. Phys. Chem. B, 2001, 105, 11067-11075.
16 G. Raynaud and R. Rapp, Oxid. Met., 1984, 21, 89-102.

17 R. Wijesundera, Semicond. Sci. Technol., 2010, 25, 045015.

18 K. Midander, P. Cronholm, H. L. Karlsson, K. Elihn, L. Möller, C. Leygraf and I. O. Wallinder, Small, 2009, 5, 389-399.

19 J.-H. Park and K. Natesan, Oxid. Met., 1993, 39, 411-435.

20 Y. Sawada, H. Tamaru, M. Kogoma, M. Kawase and K. Hashimoto, J. Phys. D: Appl. Phys., 1996, 29, 2539.

21 H. Wieder and A. Czanderna, J. Phys. Chem., 1962, 66, 816821.

22 H.-J. Hwang, K.-H. Oh and H.-S. Kim, Sci. Rep., 2016, 6, 19696.

23 J. Ryu, H.-S. Kim and H. T. Hahn, J. Electron. Mater., 2011, 40, 42-50.

24 K. Barick, M. Aslam, V. P. Dravid and D. Bahadur, J. Phys. Chem. C, 2008, 112, 15163-15170.

25 T. H. Tran and V. T. Nguyen, Int. Scholarly Res. Not., 2014, 2014, 14. 